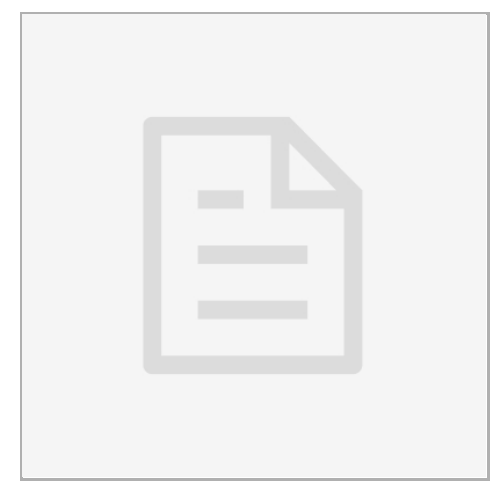

DEC 01, 2017

\title{
(3) Measuring stigma for key populations: Protocol for a systematic review measuring stigma affecting sex workers (SW) and men who have sex with men (MSM) [ P PLOS One
}

Alanna Fitzgerald-Husek ${ }^{1}$, Michael J. Van Wert, Whitney F. Ewing, Ashley L. Grosso, Claire E. Holland, Rachel Katterl, Lori Rosman, Arnav Agarwal, Stefan D. Baral

${ }^{1}$ Dalla Lana School of Public Health, University of Toronto<smiles>C1CCCCCC1</smiles>

Alanna Fitzgerald-Husek

\section{ATTACHMENTS \\ Stigma Key Populations Protocol.pdf}

\section{External link:}

https://doi.org/10.1371/journa I. pone. 0188393

\section{Protocol Citation: Alanna} Fitzgerald-Husek, Michael J. Van Wert, Whitney F. Ewing, Ashley L. Grosso, Claire E. Holland, Rachel Katterl, Lori Rosman, Arnav Agarwal, Stefan D. Baral 2017. Measuring stigma for key populations: Protocol for a systematic review measuring stigma affecting sex workers (SW) and men who have sex with men (MSM). protocols.io

https://dx.doi.org/10.17504/p rotocols.io.ka6cshe

\section{MANUSCRIPT CITATION:}

Fitzgerald-Husek A, Wert MJV, Ewing WF, Grosso AL, Holland CE, Katterl R, Rosman L, Agarwal A, Baral SD (2017) Measuring stigma affecting sex workers (SW) and men who have sex with men (MSM): A systematic review. PLoS ONE 12(11): e0188393. doi: 10.1371/journal.pone.018839 $\underline{3}$

Stigma Key

Populations

Protocol.pdf

\section{ATTACHMENTS}

Stigma Key

Populations

Protocol.pdf 
License: This is an open access protocol distributed under the terms of the Creative Commons Attribution License, which permits unrestricted use, distribution, and reproduction in any medium, provided the original author and source are credited

Protocol status: Working

Created: Oct 14, 2017

Last Modified: Mar 20, 2018

\section{PROTOCOL integer ID:}

8254

Keywords: stigma, sex work, sex worker, men who have sex with men, MSM, HIV, key population 